\title{
The Effect of External Magnetic Field on Microstructure and Magnetic Properties of Melt-Spun Nd-Fe-B/Fe-Co Nanocomposite Ribbons
}

\author{
Xuan Truong Nguyen, ${ }^{1}$ Hong Ky Vu, ${ }^{1}$ Hung Manh Do, ${ }^{1}$ \\ Van Khanh Nguyen, ${ }^{2}$ and Van Vuong Nguyen ${ }^{1}$ \\ ${ }^{1}$ Institute of Materials Science, Vietnam Academy of Science and Technology (VAST), 18 Hoang Quoc Viet Street, \\ Cau Giay District, Ha Noi 10000, Vietnam \\ ${ }^{2}$ Hanoi National University of Education, 136 Xuan Thuy Street, Cau Giay District, Ha Noi 10000, Vietnam \\ Correspondence should be addressed to Van Vuong Nguyen; vuongnv@ims.vast.ac.vn
}

Received 30 May 2013; Accepted 12 August 2013

Academic Editor: Pavel Lejcek

Copyright ( 2013 Xuan Truong Nguyen et al. This is an open access article distributed under the Creative Commons Attribution License, which permits unrestricted use, distribution, and reproduction in any medium, provided the original work is properly cited.

The ribbons $\mathrm{Nd}_{2} \mathrm{Fe}_{14} \mathrm{~B} / \mathrm{Fe}$-Co were prepared with the nominal composition $\mathrm{Nd}_{16} \mathrm{Fe}_{76} \mathrm{~B}_{8} / 40 \%$ wt. $\mathrm{Fe}_{65} \mathrm{Co}_{35}$ by the conventional and the developed magnetic field-assisted melt-spinning (MFMS) techniques. Both ribbons are nanocomposites with the smooth single-phase-like magnetization loops. The $0.32 \mathrm{~T}$ magnetic field perpendicular to the wheel surface and assisting the melt-spinning process reduces the grain size inside the ribbon, increases the texture of the ribbon, improves the exchange coupling, and, in sequence, increases the energy product $(\mathrm{BH})_{\max }$ of the isotropic powdered samples of MFMS ribbon in $~ 9 \%$ by comparison with that of the ribbon melt-spun conventionally. The grain size reduction effect caused by the assisted magnetic field has also been described quantitatively. The MFMS technique seems to be promising for producing high-performance nanocomposite ribbons.

\section{Introduction}

The high-performance nanocomposite Nd-Fe-B ribbons have been studied for almost 30 years focusing on the phase mixtures, changing the ratio of component elements of the original alloy, and changing the conditions of melt-spun process in order to create an appropriate hard/soft nanocomposite microstructure with an improved anisotropy for the ribbons. In general, the values of $(\mathrm{BH})_{\max }$ could be beyond the threshold value of $20 \mathrm{MG}$.Oe, but mainly they are in the range of 12-18 MG.Oe [1-6].

Several works reported the $(\mathrm{BH})_{\max }$ threshold value by using complicated technologies [7-11]. The value of 20.3 MG.Oe was achieved in [7] by using a multielement original alloy $(\mathrm{Pr}, \mathrm{Tb})_{2}(\mathrm{Fe}, \mathrm{Nb}, \mathrm{Zr})_{14} \mathrm{~B} / \alpha-\mathrm{Fe}$ and a strict control of microstructure to get a uniform distribution of $\alpha$ $\mathrm{Fe}$, but the repeat of this technology faces many difficulties. A stringent control of the heating temperature of the starting alloy at $1360^{\circ} \mathrm{C}$ was required to prepare the ribbons with the $(\mathrm{BH})_{\max }=21 \mathrm{MG}$.Oe [8]. The value of 22MG.Oe was obtained in [9] by controlling the excess amount of $\mathrm{FeCo}$ in the starting alloy $\mathrm{Nd}_{9.5}\left(\mathrm{Fe}_{x} \mathrm{Co}_{y}\right) \mathrm{B}_{5.5}$. The $(\mathrm{BH})_{\max }$ of about 20-22.5 MG.Oe for rapid quenched ribbons was also reported in [10]. However, to achieve these values, the authors used the combination of doped Pr, Dy, and Co. These elements increase the degree of freedom and thus reduce the stability of the technology. The value of 26.2 MG.Oe found for asspun $\mathrm{Pr}_{8} \mathrm{Fe}_{75} \mathrm{Co}_{10} \mathrm{NbB}_{5} \mathrm{C}$ can be assumed to originate from the doped $\mathrm{Pr}, \mathrm{Co}, \mathrm{Nb}$, and $\mathrm{C}$ elements and the homogeneous distribution of $\mathrm{NbC}$ phase at grain boundaries of the hard magnetic grains [11]. These high-performance abovementioned samples were difficult to be employed.

Recently, the hard magnetic shell/soft magnetic core was prepared easily by the magnetic field assisted melt-spinning technique [12]. For Nd-Fe-B system, during the field assisted melt-spinning process, the $\alpha$-Fe seeds are formed initially on the wheel surface, and the hard magnetic Nd-Fe-B grains are then grown on the seeds along the temperature gradient 
perpendicular to the ribbon plane. This process creates (001) texture of the ribbons as mentioned in [12], and the magnetic field increases the volume energy of seeds and thus decreases their critical size and, consequently, decreases the average grain size.

This paper presents the recent research results for the nanocomposite $\mathrm{Nd}_{2} \mathrm{Fe}_{14} \mathrm{~B} / \mathrm{Fe}$-Co ribbons prepared by the conventional and the magnetic field assisted melt-spinning techniques. The $\mathrm{Nd}_{16} \mathrm{Fe}_{76} \mathrm{~B}_{8}$ and $\mathrm{Fe}_{65} \mathrm{Co}_{35}$ alloys were used as the starting alloys for the melt-spinning process instead of the single alloy $\mathrm{Nd}-\mathrm{Fe}-\mathrm{Co}-\mathrm{B}$. The alloy $\mathrm{Nd}_{16} \mathrm{Fe}_{76} \mathrm{~B}_{8}$ allows to form the matrix of the phase $\mathrm{Nd}_{2} \mathrm{Fe}_{14} \mathrm{~B}$ with the $\mathrm{Nd}$-rich phase located on the grain boundaries [13]. The $\mathrm{Fe}_{65} \mathrm{Co}_{35}$ alloy is considered as the addition of a high magnetization soft phase. The role of the magnetic field assisting the melt-spinning process in reducing the grain size, enhancing the ribbon texture, and improving the energy product of nanocomposite $\mathrm{Nd}-\mathrm{Fe}-\mathrm{B} / \mathrm{Fe}-\mathrm{Co}$ ribbons will be shown and discussed in detail.

\section{Materials and Methods}

The prealloys with the compositions of $\mathrm{Fe}_{65} \mathrm{Co}_{35}$ and $\mathrm{Nd}_{16} \mathrm{Fe}_{76} \mathrm{~B}_{8}$ were arc-melted from the starting high-purity 99.9\% metals $\mathrm{Nd}, \mathrm{Fe}, \mathrm{Co}$, and $\mathrm{FeB}$ alloys under Argon atmosphere. The ingots were melted three times to obtain a high-homogeneity. In a typical procedure, the total amount of $\sim 20 \mathrm{~g}$ of these prealloys was melt-spun onto a cooper wheel under $0.05 \mathrm{MPa}$ Argon atmosphere from a quartz tube. The copper wheel has been equipped with the magnetic field oriented perpendicular to the wheel surface. The field strength measured directly on the wheel surface is $0.32 \mathrm{~T}$. The quartz tube orifice diameter was fixed at $1.0 \mathrm{~mm}$, and the distance between the nozzle and the wheel surface was kept constant by $5 \mathrm{~mm}$. The composition and structure were examined by X-ray diffraction (XRD) patterns carried out by using SIEMENS D5000 X-ray diffractometer with $\mathrm{Cu}$ $\mathrm{K} \alpha$ radiation. The phase composition analysis was performed by using the JADE software with Rietveld refinement option for the patterns with all the diffraction peaks taken in the $2 \theta$ range from $22^{\circ}$ to $88^{\circ}$. The morphology of the ribbon was studied by using Hitachi-S4800 field emission scanning electron microscopy (FESEM). The hysteresis loops of the ribbons were measured by the pulsed field magnetometer (PFM) under an applied field up to $90 \mathrm{kOe}$.

\section{Results and Discussion}

To check the effect of the assisted magnetic field on the melt-spinning process of nanocomposite ribbons, the ribbons were melt-spun with the weight ratio of the two prealloys $\mathrm{Nd}_{16} \mathrm{Fe}_{76} \mathrm{~B}_{8}: \mathrm{Fe}_{65} \mathrm{Co}_{35}=1: 0.4$. The wheel speeds used for preparing all the ribbons ranged from 25 to $37 \mathrm{~m} / \mathrm{s}$ to find an optimal wheel speed. The optimal wheel speeds without and with $0.32 \mathrm{~T}$ magnetic field are $v_{\mathrm{opt}(\mathrm{H}=0)}=34 \mathrm{~m} / \mathrm{s}$ and $v_{\text {opt }(\mathrm{H}=0.32 \mathrm{~T})}=30 \mathrm{~m} / \mathrm{s}$, respectively. The main results used below for highlighting the effect of the field have been taken for the ribbons melt-spun at these optimal speeds.

From the XRD pattern of the powdered sample of FeCo pre-alloy (see Figure 1(a)), one can realize that all the

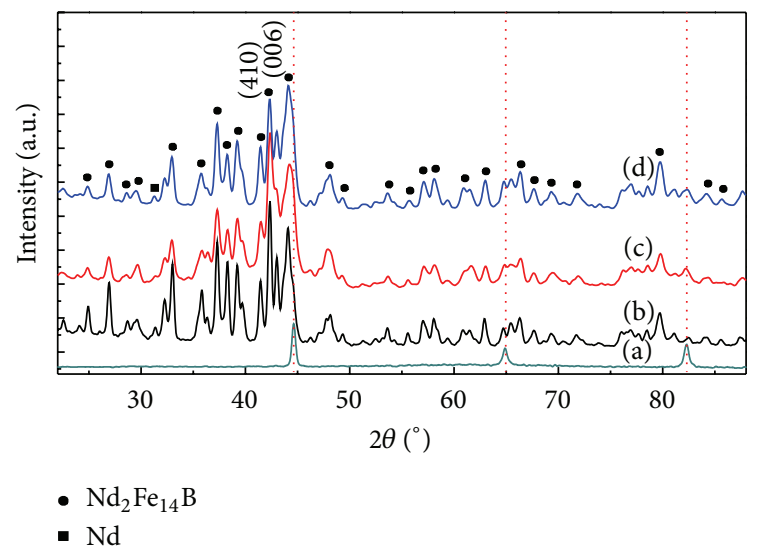

FIGURE 1: XDR diagrams of (a) $\mathrm{Fe}_{65} \mathrm{Co}_{35}$ alloy, (b) $\mathrm{Nd}_{16} \mathrm{Fe}_{76} \mathrm{~B}_{8}$ alloy, (c) melt-spun $\mathrm{Nd}_{16} \mathrm{Fe}_{76} \mathrm{~B}_{8} / 40 \%$ wt. $\mathrm{Fe}_{65} \mathrm{Co}_{35}$ ribbon without assisted magnetic field, and (d) melt-spun $\mathrm{Nd}_{16} \mathrm{Fe}_{76} \mathrm{~B}_{8} / 40 \%$ wt. $\mathrm{Fe}_{65} \mathrm{Co}_{35}$ ribbon with assisted magnetic field. The dashed curves indicate the phase of $\mathrm{Fe}_{65} \mathrm{Co}_{35}$.

diffraction peaks were attributed to $\mathrm{Fe}_{65} \mathrm{Co}_{35}$ phase and no other impurity phase was detected. Figure 1(b) shows the XRD pattern of the alloy arc-melted with the nominal composition $\mathrm{Nd}_{16} \mathrm{Fe}_{76} \mathrm{~B}_{8}$. This alloy contains mainly the peaks of $\mathrm{Nd}_{2} \mathrm{Fe}_{14} \mathrm{~B}$ phase except the peak of the cubic phase of $\mathrm{Nd}$ which appeared at 2-theta angle of $30.59^{\circ}$. The Nd excess amount of about $3 \%$ wt. of $\mathrm{Nd}_{16} \mathrm{Fe}_{76} \mathrm{~B}_{8}$ pre-alloy was derived from Rietveld analysis and corresponds to the Nd-rich phase located on the grain boundaries of ribbons.

By using these two prealloys, the $\mathrm{Nd}_{16} \mathrm{Fe}_{76} \mathrm{~B}_{8} / 40 \%$ wt. $\mathrm{Fe}_{65} \mathrm{Co}_{35}$ ribbons were melt-spun without and with the assisted magnetic field. The XRD patterns of powdered samples of these ribbons were shown in Figures 1(c) and 1(d). In these ribbons, the undepressed peak of $\mathrm{Nd}$ at $2 \theta=30.59^{\circ}$ reveals that the added $\mathrm{Fe}_{65} \mathrm{Co}_{35}$ did not react with the excess of $\mathrm{Nd}$. Furthermore, the added $\mathrm{Fe}_{65} \mathrm{Co}_{35}$ atoms are welldispersed in the matrix phase of $\mathrm{Nd}_{2} \mathrm{Fe}_{14} \mathrm{~B}$ resulting in the enhancement of the peak intensity ratio between the peaks (006) and (401), $I_{(006)} / I_{(410)}$, observed in both XRD patterns shown in Figures $1(\mathrm{c})$ and $1(\mathrm{~d})$. This enhancement is caused by the superposition of the peak (006) of the $\mathrm{Nd}_{2} \mathrm{Fe}_{14} \mathrm{~B}$ phase and the peak (110) of the fcc Fe/Co phase. It is worthy also to note that this enhancement is larger for the ribbon melt-spun in the assisted magnetic field.

The mentioned dispersion and enhancement effects of the peak ratio can be explained by the fact that during magnetic field assisted melt-spinning (MFMS) process the soft phase Fe/Co seeds are formed on the wheel surface at temperature far below their Curie temperatures. Staying in the ferromagnetic state, these seeds absorb the energy from the external magnetic field resulting not only in the decrease of their critical size as shown below, but also in splitting continuous cooling transformation (CCT) diagram into CCT diagrams of $\mathrm{Fe} / \mathrm{Co}$ and $\mathrm{Nd}_{2} \mathrm{Fe}_{14} \mathrm{~B}$ subsystems [13].

The field assisted texture enhancement is clearer to be seen by comparing the XRD patterns taken on the free surfaces of these ribbons melt-spun with and without a field 


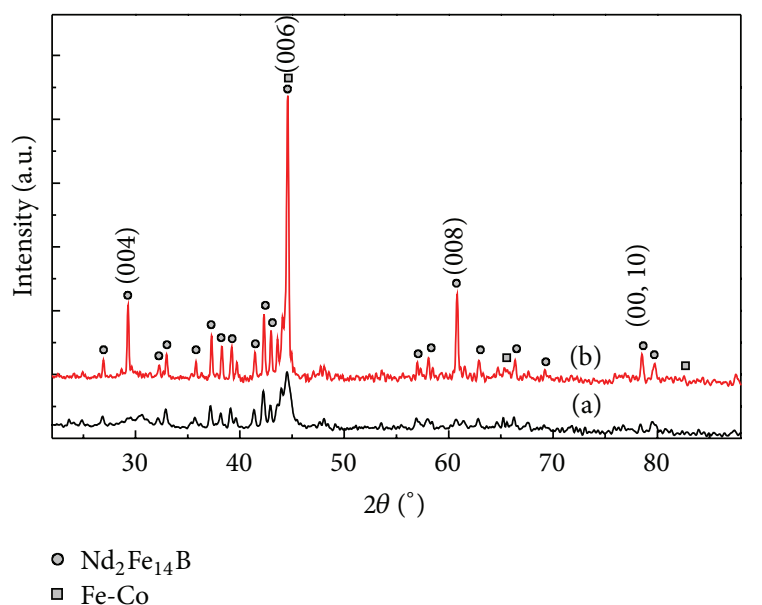

FIGURE 2: XDR patterns of $\mathrm{Nd}_{16} \mathrm{Fe}_{76} \mathrm{~B}_{8} / 40 \%$ wt. $\mathrm{Fe}_{65} \mathrm{Co}_{35}$ ribbons taken on their free surface: (a) the ribbon melt-spun without the assisted magnetic field and (b) the ribbon with the assisted magnetic field of $0.32 \mathrm{~T}$.

(see Figure 2). The strong texture of (001) peaks has appeared on the pattern of MFMS ribbon. This texture enhancement of MFMS ribbons was observed also for the single-phase $\mathrm{Nd}_{2} \mathrm{Fe}_{14} \mathrm{~B}$ [12] and nanocomposite $\mathrm{Nd}_{16} \mathrm{Fe}_{76} \mathrm{~B}_{8} / 30 \%$ wt. $\mathrm{Fe}_{65} \mathrm{Co}_{35}$ ribbons [13].

The grain refinement effect of the magnetic field assisted melt-spinning process of the single-phase $\mathrm{Nd}_{2} \mathrm{Fe}_{14} \mathrm{~B}$ ribbons (mentioned in [12]) is also clearly observed in the studied nanocomposite ribbon melt-spun in the magnetic field $0.32 \mathrm{~T}$ oriented perpendicular to the wheel surface as shown by the FESEM images of both ribbons melt-spun with and without the field presented in Figure 3. It is commonly recognized that the grain size is reduced by increasing the wheel speed. So, naturally, the size of grains of the ribbon melt-spun at $30 \mathrm{~m} / \mathrm{s}$ must be bigger than that of the ribbon melt-spun at $34 \mathrm{~m} / \mathrm{s}$, but this grain size of the ribbon melt-spun at the wheel speed $30 \mathrm{~m} / \mathrm{s}$ is reduced further by the applied field of $0.32 \mathrm{~T}$. This field effect of reducing the grain size results in the same grain size in the range of 50-100 nm observed in both ribbons. Moreover, the grain size distribution of the ribbon melt-spun in the field is narrower than that of the ribbon melt-spun without a field.

The grain size reduction caused by the magnetic field assisted melt-spinning process can be described qualitatively as shown below.

The melt-spinning technique creates a nonequilibrium crystalline growth under a very high undercooling degree, $\Delta T$, oriented perpendicular to the wheel surface. The crystalline growth begins with the seed formation which starts with a solid-liquid interface appearance with the tension $\gamma_{\mathrm{SL}}$. $A$, where $\gamma_{\mathrm{SL}}$ is the tension density and $A$ is the interface area. By the undercooling degree $\Delta T$, the seed can be developed if its size is equal to or larger than the critical size $r^{*}$ which is determined from the balance between the surface and volume energy of seeds; otherwise, if the volume energy cannot be kept enough, then the seed disappears. The crystalline growth

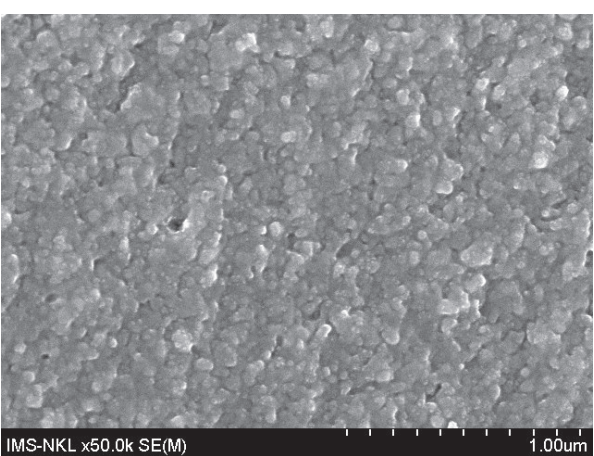

(a)

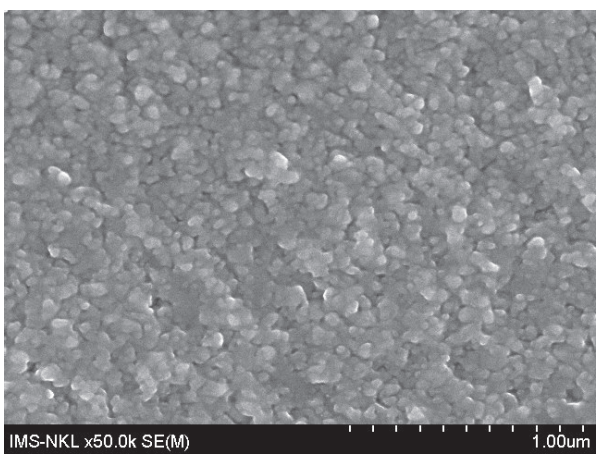

(b)

FIGURE 3: FESEM micrograph of the as-spun $\mathrm{Nd}_{16} \mathrm{Fe}_{76} \mathrm{~B}_{8} / 40 \%$ wt. $\mathrm{Fe}_{65} \mathrm{Co}_{35}$ ribbons: (a) $v_{\text {opt }}=34 \mathrm{~m} / \mathrm{s}$ without the assisted magnetic field and (b) $v_{\text {opt }}=30 \mathrm{~m} / \mathrm{s}$ in the magnetic field $0.32 \mathrm{~T}$.

is continued by joining other atoms to the formed seeds. The critical size of the seed is as follows [14]:

$$
r^{*}=\frac{3 \gamma_{\mathrm{SL}}}{\left(\Delta H_{f} * \Delta T\right) / T_{m}} .
$$

Here, $\Delta H_{f}$ is the latent heat of fusion and $T_{m}$ is the melting temperature. In the melt-spinning experiments, where the latent heat of the solidification process is absorbed by the cooper wheel, the critical size of seeds is also controlled by the wheel speed as follows:

$$
r^{*}=\frac{3 \gamma_{\mathrm{SL}}}{\left(\Delta E_{\mathrm{vol}}\left(v_{w}\right) * \Delta T\right) / T_{m}},
$$

where $\Delta E_{\mathrm{vol}}$ is the energy uptake in the volume of seeds, which is dependent on the wheel thermal absorption ability $\alpha$ which, in turn, depends on the wheel speed $v_{w}$. The relation between $\Delta E_{\mathrm{vol}}$ and $\Delta H_{f}$ is suggested to be

$$
\Delta E_{\mathrm{vol}}\left(v_{w}\right)=\frac{\Delta H_{f}}{\alpha\left(v_{w}\right)} .
$$

It is understood that when the melt-spinning process occurs in a magnetic field and if the seed is ferromagnetic, then a part of volume energy must be changed by the amount of energy absorbed from the external field into the seed volume. It is 
TABLE 1: The summary of parameters of samples: the samples are the powdered ribbons, the self-demagnetization factor $D=0.33$, and the mass density $\rho=7.6 \mathrm{~g} / \mathrm{cm}^{3}$.

\begin{tabular}{|c|c|c|c|c|c|c|c|c|}
\hline Composition & $\begin{array}{l}\text { External } \\
\text { magnetic } \\
\text { field }(\mathrm{T})\end{array}$ & $\begin{array}{l}\text { Optimal wheel } \\
\text { speed }(\mathrm{m} / \mathrm{s})\end{array}$ & $\begin{array}{c}B_{r} \\
\left(\mathrm{~A} * \mathrm{~m}^{2} / \mathrm{kg}\right)\end{array}$ & $B_{r}(\mathrm{~T})$ & $M_{r} / M_{s}$ & $\begin{array}{c}{ }_{i} H_{c} \\
(\mathrm{kA} / \mathrm{m})\end{array}$ & $\begin{array}{c}{ }_{b} H_{c} \\
(\mathrm{kA} / \mathrm{m})\end{array}$ & $\begin{array}{l}(\mathrm{BH})_{\max } \\
\left(\mathrm{kJ} / \mathrm{m}^{3}\right)\end{array}$ \\
\hline $\begin{array}{l}\mathrm{Nd}_{16} \mathrm{Fe}_{76} \mathrm{~B}_{8} / \\
40 \% \text { wt. } \mathrm{Fe}_{65} \mathrm{Co}_{35}\end{array}$ & 0.0 & 34 & 89.2 & 0.93 & 0.61 & 505 & 383 & 128 \\
\hline $\begin{array}{l}\mathrm{Nd}_{16} \mathrm{Fe}_{76} \mathrm{~B}_{8} / \\
40 \% \text { wt. } \mathrm{Fe}_{65} \mathrm{Co}_{35}\end{array}$ & 0.32 & 30 & 92.3 & 0.99 & 0.63 & 675 & 504 & 140 \\
\hline
\end{tabular}

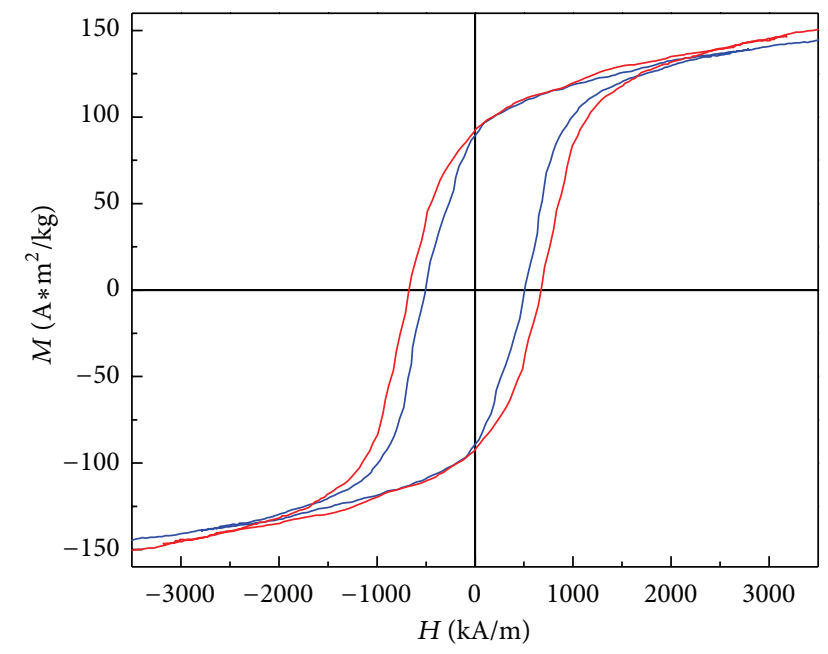

Figure 4: Hysteresis loops of $\mathrm{Nd}_{16} \mathrm{Fe}_{76} \mathrm{~B}_{8} / 40 \%$ wt. $\mathrm{Fe}_{65} \mathrm{Co}_{35}$ samples with and without a magnetic field. Blue line is $M(H)$ of ribbons with $H_{\text {ext }}=0 \mathrm{~T}$ and $v_{\text {opt }}=34 \mathrm{~m} / \mathrm{s}$ and red line is $M(H)$ of ribbons with $H_{\text {ext }}=0.32 \mathrm{~T}$ and $v_{\text {opt }}=30 \mathrm{~m} / \mathrm{s}$.

easy to be shown that the formula of the critical size of seeds in this case becomes

$$
r^{*}=\frac{3 \gamma_{\mathrm{SL}}}{\left(\left\{\Delta E_{\mathrm{vol}}\left(v_{w}\right)+0.5 *(M * H)\right\} * \Delta T\right) / T_{m}} .
$$

Equation (4) shows that the critical size of ferromagnetic seeds decreased by increasing the strength of the external magnetic field assisted melt-spinning process. This effect leads to the decrease of the average size of grains of ribbons melt-spun in a magnetic field in comparison with the case of ribbons melt-spun without a field.

The magnetic properties of powdered melt-spun samples were shown in Figure 4. The hysteresis loops of both $\mathrm{Nd}_{16} \mathrm{Fe}_{76} \mathrm{~B}_{8} / 40 \%$ wt. $\mathrm{Fe}_{65} \mathrm{Co}_{35}$ ribbons are nonkink and smooth indicating the existence of an effective exchange coupling between the hard and soft magnetic phases.

The effect of the assisted field results in increasing the magnetization $M_{s}$ and the coercivity ${ }_{i} H_{c}$ for the ribbon melt-spun at $30 \mathrm{~m} / \mathrm{s}$ in the field $0.32 \mathrm{~T}$ in comparison with that of the ribbon melt-spun at $34 \mathrm{~m} / \mathrm{s}$ without a field. This improvement leads to the higher value of $(\mathrm{BH})_{\max }, 140 \mathrm{~kJ} / \mathrm{m}^{3}$ of the ribbon melt-spun with the field in comparison with $128 \mathrm{~kJ} / \mathrm{m}^{3}$ of the ribbon melt-spun without a field. All the parameters of the studied samples were summarized in Table 1.

\section{Conclusions}

The nanocomposite ribbons with the nominal composition $\mathrm{Nd}_{16} \mathrm{Fe}_{76} \mathrm{~B}_{8}+40 \%$ wt. $\mathrm{Fe}_{65} \mathrm{Co}_{35}$ have been prepared by using the conventional and the developed magnetic field assisted melt-spinning techniques. The experimental data show that the magnetic field perpendicular to the wheel surface reduces the grain size of the ribbons. The field strength $0.32 \mathrm{~T}$ has the same effect in reducing the grain size as the wheel speed increment of $4 \mathrm{~m} / \mathrm{s}$. Moreover, the field also enhances the texture (00l) and the exchange coupling in the ribbon melt-spun in the magnetic field in comparison with the ribbon melt-spun without the magnetic field, which increases the energy product by $\sim 9 \%$, from 128 to $140 \mathrm{~kJ} / \mathrm{m}^{3}$. The quantitative description of the field effect of the grain size reduction has also been derived. The obtained results reveal that the magnetic field assisted melt-spinning technique is an advantaged tool for producing high-quality nanocomposite ribbons.

\section{Acknowledgments}

This paper is supported by Vietnam's National Foundation for Science and Technology Development (NAFOSTED), code: 103.02-2010.05. The authors also gratefully thank the Key Laboratory of Electronic Materials and Devices, Institute of Materials Science of VAST, for providing experimental facilities.

\section{References}

[1] I. Ahmad, H. A. Davies, and R. A. Buckley, "The effect of Nd content on the structure and properties of melt spun Nd-rich NdFeB alloys," Journal of Magnetism and Magnetic Materials, vol. 157-158, pp. 31-32, 1996.

[2] Z. Chen, Y. Zhang, G. C. Hadjipanayis, Q. Chen, and B. Ma, "Effect of wheel speed and subsequent annealing on the microstructure and magnetic properties of nanocomposite $\operatorname{Pr}_{2} \mathrm{Fe}_{14} \mathrm{~B} /$ $\alpha$-Fe magnets," Journal of Magnetism and Magnetic Materials, vol. 206, no. 1, pp. 8-16, 1999.

[3] G. Mendoza-Suárez, J. I. Escalante-García, J. López-Cuevas, G. Vargas-Gutiérrez, H. Mancha-Molinar, and J. Mendez-Nonell, "Effect of roll speed on the magnetic properties of nanocomposite $\mathrm{PrFeB}$ magnets prepared by melt-spinning," Journal of 
Magnetism and Magnetic Materials, vol. 206, no. 1, pp. 37-44, 1999.

[4] W.-Y. Zhang, S.-Y. Zhang, A.-R. Yan, H.-W. Zhang, and B.-G. Shen, "Effect of the substitution of Pr for Nd on microstructure and magnetic properties of nanocomposite $\mathrm{Nd}_{2} \mathrm{Fe}_{14} \mathrm{~B} / \alpha$ - $\mathrm{Fe}$ magnets," Journal of Magnetism and Magnetic Materials, vol. 225, no. 3, pp. 389-393, 2001.

[5] Y. Sen, S. Xiaoping, and D. Youwei, "Exchange coupled $\mathrm{Nd}_{2} \mathrm{Fe}_{14} \mathrm{~B} / \alpha$-Fe nanocomposite magnets with fine $\alpha$-Fe grains," Microelectronic Engineering, vol. 66, no. 1-4, pp. 121-127, 2003.

[6] W. Chen, X. Zhao, J. J. Hu et al., "Refinement of the microstructure and enhancement of the magnetic properties in $\alpha$ $\mathrm{Fe} /(\mathrm{Nd}, \mathrm{Dy})_{2} \mathrm{Fe}_{14} \mathrm{~B}$ nanocomposite using the two-step annealing technique," Journal of Magnetism and Magnetic Materials, vol. 306, no. 1, pp. 51-54, 2006.

[7] Z. Q. Jin, H. Okumura, Y. Zhang, H. L. Wang, J. S. Muoz, and G. C. Hadjipanayis, "Microstructure refinement and significant improvements of magnetic properties in $\operatorname{Pr}_{2} \mathrm{Fe}_{14} \mathrm{~B} / \alpha$ - $\mathrm{Fe}$ nanocomposites," Journal of Magnetism and Magnetic Materials, vol. 248, no. 2, pp. 216-222, 2002.

[8] D. Sultana, M. Marinescu, Y. Zhang, and G. C. Hadjipanayis, "Isotropic nanocomposite $\mathrm{Pr}-\mathrm{Fe}-\mathrm{Co}-\mathrm{B}$ ribbons with $(\mathrm{BH})_{\max }>$ 20 MGOe," Physica B, vol. 384, no. 1-2, pp. 306-309, 2006.

[9] A. Melsheimer, M. Seeger, and H. Kronmüller, "Influence of Co substitution in exchange coupled $\mathrm{NdFeB}$ nanocrystalline permanent magnets," Journal of Magnetism and Magnetic Materials, vol. 202, no. 2, pp. 458-464, 1999.

[10] Z. W. Liu and H. A. Davies, "The practical limits for enhancing magnetic property combinations for bulk nanocrystalline NdFeB alloys through Pr, Co and Dy substitutions," Journal of Magnetism and Magnetic Materials, vol. 313, no. 2, pp. 337-341, 2007.

[11] Y. . Bai, Z. Lei, S. Baogen, Z. Tongyun, and Y. Ronghai, “Highperformance $\alpha$-e/ $\operatorname{Pr}_{2} \mathrm{Fe}_{14}$ B-type nanocomposite magnets fabricated by direct melt spinning," Journal of Rare Earths, vol. 31, no. 1, pp. 49-453, 2013.

[12] V. V. Nguyen, C. Rong, Y. Ding, and J. P. Liu, "Effect of magnetic fields on melt-spun $\mathrm{Nd}_{2} \mathrm{Fe}_{14}$ B-based ribbons," Journal of Applied Physics, vol. 111, Article ID 07A731, 2012.

[13] N. X. Truong, V. H. Ky, N. V. Khanh, and N. V. Vuong, "The microstructure and magnetic properties of magnetic field assisted melt-spun ribbons $\mathrm{Nd}_{2} \mathrm{Fe}_{14} \mathrm{~B} / \alpha$-FeCo," in Proceedings of the 6th International workshop on Advanced Materials Science and Nanotechnology, Ha Long City, Vietnam, 2012.

[14] G. Dhanaraj, K. Byrappa, V. Prasad, and M. Dudley, Eds., Handbook of Crystal Growth, chapter 2, Sringer, Berlin, Germany, 2010. 

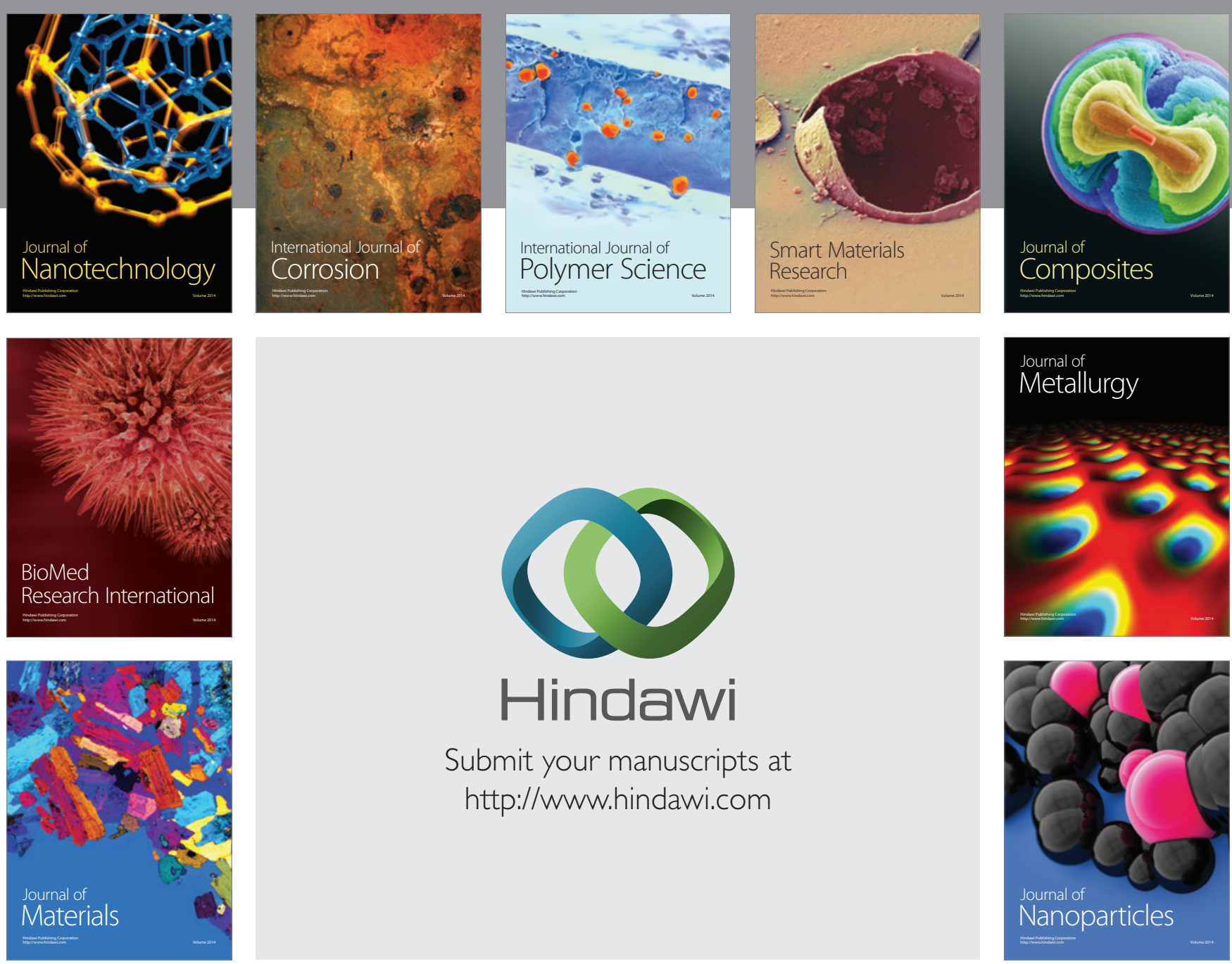

Submit your manuscripts at http://www.hindawi.com
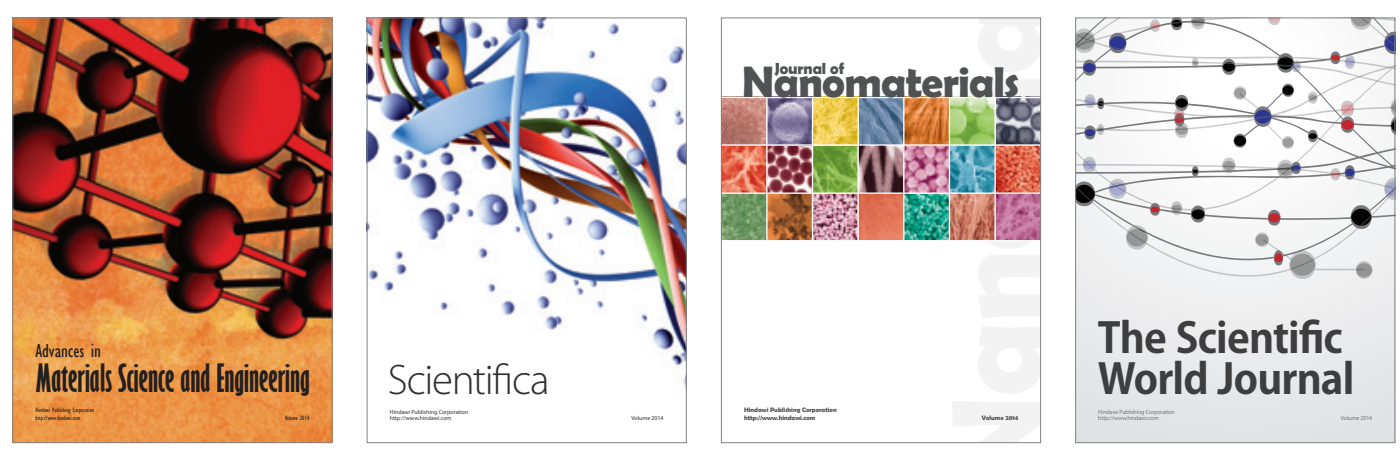

\section{The Scientific World Journal}
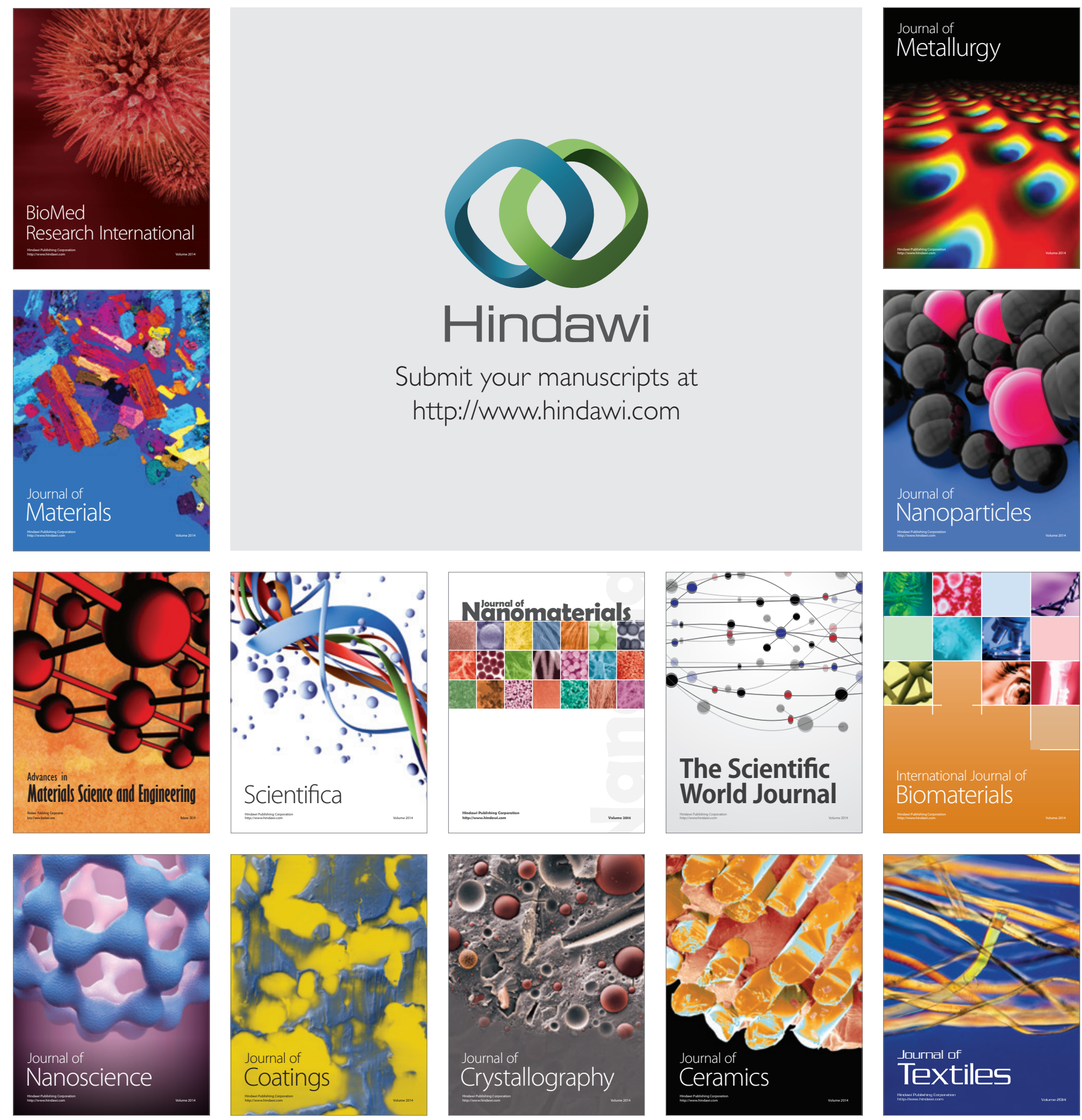